\title{
Effects of organic products with insecticidal action on key insect pests in alfalfa seed production
}

\author{
Ivelina Mitkova Nikolova* \\ Department of Tehnology and Ecology of Forage Crops, Institute of Forage Crops General Vladimir Vazov 89, 5800 Pleven, Bulgaria
}

\section{A B S T R A C T}

\begin{abstract}
A trial was conducted in the experimental field of the Institute of Forage Crops, Bulgaria, over the period 2012-2014 with alfalfa wich grew for seed production. It was studied the action of three insecticides (two biological/NeemAzal T/S and Pyrethrum FS EC/and one synthetic insecticide Nurelle D - standard) to a control of lucerne seed weevil, Tychius flavus Beck. (Coleoptera: Curculionidae); alfalfa plant bug, Adelphocoris lineolatus Goeze (Hemiptera, Heteroptera: Miridae) and pea aphid, Acyrthosiphon pisum Harr. (Hemiptera, Sternorrhyncha: Aphididae) - major pests in alfalfa seed production. The method of sweeping with entomological net was used. Organic products were most effective against $A$. pisum. Increasing efficacy of NeemAzal reached satisfactory values of 67.8 and 69.1 percent of the seventh and ninth day after the application. Pyrethrum exhibited strong efficacy throughout the reporting period in the range $73.9-82.8 \%$ and differences between bioinsecticides were significant. In compared with standard its toxic action after the fifth day was approached the effect of synthetic insecticide with minor differences between them. Bioinsecticides exhibited good control against $A$. lineolatus as the trend of the better protective effect of Pyrethrum was retained. A dominant influence on the efficacy variation and seed productivity had the type of insecticide followed by factors year of treatment. The productivity of alfalfa grown for seed production realized after application of Pyrethrum significantly exceeded control and was comparable to that of Nurelle D.
\end{abstract}

Keywords: Alfalfa; Efficacy; NeemAzal T/S; Pyrethrum FS EC; Seed insect pest

\section{INTRODUCTION}

The major pests of alfalfa seed-growing areas are lygus bugs (Lygus spp.), alfalfa seed chalcid (Bruchophagus roddi), alfalfa seed weevil (Tychius flavus Beck) and various species of aphids, including pea aphid (Acyrthosiphon pisum), spotted alfalfa aphid (Therioaphis maculata), and cowpea aphid (Aphis craccivora) (Karagić et al., 2010; Lugić et al., 2010). Insect pests can reduce yield and/or quality of alfalfa seed because of the damage which they were done (Godfrey et al., 2013).

Feeding on alfalfa commonly results in abscission of reproductive structures, deformation of fruits and seeds, and altered patterns of growth (Goplen et al., 1987). Plant bugs are a particular threat to alfalfa seed crops, because the seed is a valuable commodity, and yield loss may result from feeding on flower buds, flowers or fruiting structures. Unlike alfalfa for hay, plant bugs in seed crops can find favoured feeding sites throughout most of the growing season, and mowing does not reduce their numbers through disturbance or habitat loss (Uddin, 2005). According to Wheeler (2001), feeding by $A$. lineolatus can reduce the yield of seed crops by $50 \%$ or more while Sekulić et al. (2005) added that in a hot and dry year, the attack of alfalfa plant bug decreased the seed yields of $20-90 \%$.

Aphids are ubiquitous and serious pests that cause substantial losses too by draining plant nutrients, injecting plant elicitors, reducing of photosynthesis, stunting and transmitting pathogenic viruses $(\mathrm{Ng}$ and Perry, 2004; Sadeghi et al., 2009). The viruses transmitted by aphids can cause severe losses. Under favorable conditions, these viruses can cause a high rate of crop failure and severe economic losses (Barbercheck, 2011).

Tychius flavus Beck is a pest of alfalfa seed crops and other legumes crops. Females of this weevil lay eggs on alfalfa pods and larva feeding and developing on seeds decreased yield and quality of alfalfa seed. Gombert et al. (2015) found that seed yield losses can reach $30 \%$ by Tychius aureolus.

\footnotetext{
${ }^{*}$ Corresponding author:

Ivelina Mitkova Nikolova, Department of Tehnology and Ecology of Forage Crops, Institute of Forage Crops General Vladimir Vazov 89 , 5800 Pleven, Bulgaria. E-mail: Himnikolova@abv.bg
} 
Plant protection from insect attack in alfalfa plants for seed production has been a major challenge in recent years in the biological agriculture. The main difference between conventional and organic insect pest management is the unavailability of synthetic pesticides for use in organic productions when the pest's number exceeds the economic threshold of harmfulness. The use of organic-approved products with insecticidal action that are effective against harmful insects is one of the methods applicable to organic cultivation.

Number plants provide natural insecticides, but their extent and their specific action often have led us to focus our research on the Neem and Chrysanthemum. These plants are also used for many uses and represent one of the economically most important classes of compounds with broad usage in integrated pest management and organic agriculture (Isman, 2006; Trdan et al., 2007). In addition, pyrethrum and neem products are environmentally friendly and safe to non-target organisms (Kraiss, Cullen, 2008a, b).

The growing interest in the use of pesticides based on extracts from these plants in the world is motivated by their efficacy comparable to those of chemical pesticides (Mouffok et al., 2007/2008). Although plant pesticides have been studied in many laboratory tests (Morgan, 2009), very few studies are available that present results from practical use. Therefore, the aim of the present study was to determine the impact of the biological insecticides NeemAzal-T/S and Pyrethrum on alfalfa seed insect pest in organic cultivation.

\section{MATERIALS AND METHODS}

A trial was conducted in the experimental field of the Institute of Forage Crops, Bulgaria, over the period 2012-2014 with alfalfa wich grew for seed production. The field trial was conducted using a long plot design with a sowing rate of $25 \mathrm{~kg} \mathrm{ha}{ }^{-1}$, plot size of $10.4 \mathrm{~m}^{2}\left(8^{*} 1.3 \mathrm{M}\right)$, in three replications and a natural background of soil supply with the major nutrients. In the long plot design, the replications are arranged in an elongate strip, i. e., the replications are arranged one after the other with the aim of equalization of the soil fertility. The trial was occupied an area of $130 \mathrm{~m}^{2}$.

It was studied the action of three insecticides to a control of lucerne seed weevil, Tychius flavus Beck. (Coleoptera: Curculionidae); alfalfa plant bug, Adelphocoris lineolatus Goeze (Hemiptera, Heteroptera: Miridae) and pea aphid, Acyrthosiphon pisum Harr. (Hemiptera, Sternorrhyncha: Aphididae) - major pests in alfalfa seed production. Alfalfa was grown for seed production and treatments were carried out at the beginning of the flowering stage in a second undergrowth (from 10-20 June). The toxicity of the insecticides was calculated according to the formula of Henderson, Tilton (1955) on the 1, 5, 7 and 9 days after second treatment. The method of sweeping with the entomological net was used.

The data were subjected to one-way ANOVA, and the means were compared by Tukey's test at $5 \%$ probability $(\mathrm{p} \leq 0.05)$. The Multiple Regression Analysis of Statgraphics Plus (1995) for Windows Ver. 2.1 Software program was used.

Trial variants and product characteristics are shown in Table 1.

\section{RESULTS AND DISCUSSION}

Weather conditions during the study years differing in regarding the weather conditions affected the insecticidal action of the tested products (Table 2). Biological insecticides NeemAzal and Pyrethrum are unstable in low temperatures and rainfall (Pavela, 2009). Therefore, the effectiveness of products was strongly influenced by the meteorological conditions during the different years. Particularly indicative in this regard was 2013 when the weather had an unfavorable impact on insecticide efficacy because of the low daily average temperatures combined with considerable rainfall during the period June 11 to $20(49.9 \mathrm{~mm}$ in compared with $1.4 \mathrm{~mm}$ in 2012 and $15.5 \mathrm{~mm}$ in 2014). In that period, the treatment was performed

Table 1: Characteristics of products

\begin{tabular}{|c|c|c|c|}
\hline Trial variants & Active ingredients & Producer & Application rates, per ha \\
\hline 1. Control (organic production) & Treated with distilled water & - & 3001 \\
\hline $\begin{array}{l}\text { 2. NeemAzal T/S } \\
\text { (organic production) }\end{array}$ & $\begin{array}{l}1 \% \text { azadirachtin } A+ \\
0.5 \% \text { azadirachtin } B, W, G, D \text { and } \\
2.5 \% \text { neem substance }\end{array}$ & $\begin{array}{l}\text { Trifolio - M, Germany } \\
\text { Product from the Indian Neem } \\
\text { tree Azadirachta indica }\end{array}$ & $500 \mathrm{ml}$ \\
\hline $\begin{array}{l}\text { 3. Pyrethrum FS EC } \\
\text { (organic production) }\end{array}$ & $\begin{array}{l}32 \% \text { extract from pyrethrum } \\
\text { (25\% pyrethrin)+32\% sesame oil+ } \\
36 \% \text { adhesives (soft potassium soap) }\end{array}$ & $\begin{array}{l}\text { Andermatt Biocontrol, Switzerland } \\
\text { Natural extract of Chrysanthemum } \\
\text { cinerariaefolium }\end{array}$ & $50 \mathrm{ml}$ \\
\hline 4.Nurelle D & $\begin{array}{l}50 \mathrm{~g} / \mathrm{l} \text { a.i. cypermethrin+500g/l a.i. } \\
\text { chlorpyrifos-ethy }\end{array}$ & $\begin{array}{l}\text { Dow AgroSciences- Indiana, USA } \\
\text { Pyrethroid insecticide }\end{array}$ & $400 \mathrm{ml}$ \\
\hline
\end{tabular}


Nikolova: Effects of bio insecticides on insect pests

Table 2: Meteorological characteristics of the Pleven region

\begin{tabular}{|c|c|c|c|c|c|c|c|c|c|c|}
\hline \multirow[t]{2}{*}{ Month } & \multirow[t]{2}{*}{ Ten days period } & \multicolumn{3}{|c|}{ Temperature, ${ }^{\circ} \mathrm{C}$} & \multicolumn{3}{|c|}{ Rainfall, mm } & \multicolumn{3}{|c|}{ Relative humidity, \% } \\
\hline & & 2012 & 2013 & 2014 & 2012 & 2013 & 2014 & 2012 & 2013 & 2014 \\
\hline \multirow{4}{*}{ April } & $1-10$ & 12.2 & 10.5 & 11.9 & 14.2 & 33.1 & 37.6 & 57 & 76 & 71 \\
\hline & $11-20$ & 14.3 & 12.5 & 9.9 & 22.1 & 17.6 & 69.9 & 66 & 65 & 82 \\
\hline & $21-30$ & 17.8 & 19.5 & 14.9 & 10.0 & 0 & 32.3 & 54 & 52 & 76 \\
\hline & Average & 14.8 & 14.2 & 12.2 & 46.3 & 50.7 & 139.8 & 59 & 65 & 76.3 \\
\hline \multirow{3}{*}{ May } & $1-10$ & 20.3 & 20.7 & 14.7 & 6.0 & 3.8 & 23.7 & 57 & 55 & 72 \\
\hline & $11-20$ & 15.7 & 20.0 & 15.9 & 28.9 & 33.3 & 16.9 & 76 & 57 & 68 \\
\hline & 21-31 & 16.3 & 18.2 & 19.4 & 50.3 & 26.6 & 42.4 & 79 & 67 & 70 \\
\hline \multirow{5}{*}{ June } & Average & 17.4 & 19.6 & 16.7 & 85.2 & 63.7 & 83 & 71 & 60 & 70.0 \\
\hline & 1-10 & 22.5 & 18.9 & 19.4 & 13.1 & 5.9 & 19.6 & 63 & 63 & 70 \\
\hline & $11-20$ & 24.7 & 23.3 & 20.8 & 1.4 & 49.9 & 15.5 & 56 & 68 & 72 \\
\hline & 21-30 & 25.0 & 21.8 & 21.7 & 25.8 & 55.8 & 19.2 & 56 & 66 & 60 \\
\hline & Average & 24.1 & 21.3 & 20.6 & 40.3 & 111.6 & 54.3 & 58 & 66 & 67 \\
\hline
\end{tabular}

over the years. Depending on weather conditions, organic products showed the highest efficacy and protected plants from pests in 2012 .

In a comparative test of biological insecticides against T. flavus in 2012, Pyrethrum showed significantly a highly toxic effect $(P<0.05)$ and protected the plants until seven days after its application with efficacy 70.1-79.4\% (Table 3). Increasing efficiency of NeemAzal reached a satisfactory value of $62.3 \%$ on the seventh day and then began decreasing. Both products reduced to a lesser extent the number of the weevils to Nurelle D as the differences between organic and synthetic products were statistically significant.

The protective effect of organic insecticides was more pronounced against $A$. lineolatus. The efficacy of NeemAzal increased by $57.4 \%$ on the first day and reached $68.2 \%$ of the ninth day after treatment. Pyrethrum exhibited significantly a stronger toxic effect with rapid initiation action (87.6\% on the first day) and long-effect (72.5\% on a ninth day after treatment). It provided a better protection of plants in compared with NeemAzal. Nurelle D had significantly the strongest toxicity $(P<0.05)$ of the first and fifth day then it was equalized with that of the Pyrethrum, as the differences between them were insignificant.

Tested products showed the highest toxic effect against A. pisum. The efficacy of NeemAzal was high on the fifth and ninth day after application and varied in the range $68.7-70.0 \%$. The insecticidal effect of NeemAzal was less pronounced with significant differences $(P<0.05)$ in compared with other products, but the bioinsecticide provided good protection against this pest species. The toxic effect of Pyrethrum was high throughout the reporting period, ranging from 76.2 to $90.0 \%$ as the seventh and ninth day after treatment it approached that of synthetic insecticide with insignificant differences between them.
Azadirachtin and Pyrethrum are reported as the most promising and effective against several types phytophagous, and special place among them occupy different species of aphids (Isman, 2005, 2006; Shannag et al., 2014). In 2012, biological products provided the best protection of plants against pea aphid, followed by alfalfa plant bug. Bioinsecticides occurred mainly as insufficiently effective against Tychius flavus and when weevils exceed the economic threshold of harmfulness, they would not have saved alfalfa from damage.

In 2013, biological insecticides manifested themselves primarily as insufficiently effective at harmful insects and the efficacy values mainly varied between 30.0 and $60 \%$. An exception was observed in Pyrethrum whose efficacy was relatively higher against $A$. lineolatus and $A$. pisum only on the first day after application (69.1-73.4\%), followed by an unsatisfactory decrease. The synthetic insecticide reserved the highly toxic action generally one week after treatment.

The impact of biological insecticides in 2014 followed a trend similar to that in 2012 on pests. Insufficiently high protective effect of NeemAzal and Pyrethrum was found against the lucerne seed weevil. Higher toxic action with significant differences $(P<0.05)$ was observed in Pyrethrum, which provided satisfactory control until the fifth day after application and the efficiency varied between $67.1-76.3 \%$. The efficacy of NeemAzal was low, as the maximum value recorded on the seventh day did not exceed $50 \%$. In compared with Nurelle D both products reduced the number of harmful insects to a considerably lesser degree as the differences between their toxic effects were statistically significant.

Bioinsecticides exhibited a better control against $A$. lineolatus (in compared with T. flavus). In NeemAzal observed satisfactory effect on the eighth and ninth day after treatment with an efficacy of 60.4 and 61.8 percent 
Table 3: Efficacy of some products against Tychius flavus, Adelphocoris lineolatus and Acyrthosyphon pisum (budding and flowering stages)

\begin{tabular}{|c|c|c|c|c|c|c|c|c|}
\hline \multirow[t]{2}{*}{ Variants } & \multicolumn{2}{|c|}{1 DAT } & \multicolumn{2}{|c|}{5 DAT } & \multicolumn{2}{|c|}{7 DAT } & \multicolumn{2}{|c|}{9 DAT } \\
\hline & E, \% & Sd & $E, \%$ & Sd & E, \% & Sd & $E, \%$ & Sd \\
\hline \multicolumn{9}{|l|}{2012} \\
\hline \multicolumn{9}{|l|}{ Tychius flavus } \\
\hline 1. NeemAzal & $43.80 a$ & 1.11 & $51.20 \mathrm{a}$ & 2.88 & $62.30 a$ & 2.04 & $57.20 \mathrm{a}$ & 1.80 \\
\hline 2. Pyrethrum & $79.40 \mathrm{~b}$ & 2.43 & $72.50 \mathrm{~b}$ & 1.36 & $70.10 \mathrm{~b}$ & 2.20 & $60.00 a$ & 2.12 \\
\hline 3. Nurelle D & $92.60 \mathrm{c}$ & 1.22 & $88.00 \mathrm{c}$ & 1.74 & $79.40 \mathrm{c}$ & 1.64 & $75.50 b$ & 1.72 \\
\hline $\mathrm{LSD}_{0.05 \%}$ & 3.383 & & 4.193 & & 3.947 & & 3.772 & \\
\hline \multicolumn{9}{|c|}{ Adelphocoris lineolatus } \\
\hline 1. NeemAzal & $57.40 \mathrm{a}$ & 2.31 & $64.10 \mathrm{a}$ & 1.82 & $67.10 \mathrm{a}$ & 2.80 & $68.20 \mathrm{a}$ & 1.64 \\
\hline 2. Pyrethrum & $87.60 \mathrm{~b}$ & 1.97 & $80.50 \mathrm{~b}$ & 1.55 & $77.20 \mathrm{~b}$ & 1.31 & $72.50 \mathrm{~b}$ & 1.55 \\
\hline 3. Nurelle D & $93.00 \mathrm{c}$ & 1.00 & $89.40 c$ & 1.60 & $81.10 \mathrm{~b}$ & 2.59 & $75.30 b$ & 2.08 \\
\hline $\operatorname{LSD}_{0.05 \%}$ & 3.684 & & 3.317 & & 4.658 & & 3.541 & \\
\hline \multicolumn{9}{|c|}{ Acyrthosiphon pisum } \\
\hline 1. NeemAzal & $61.70 a$ & 1.80 & $68.70 a$ & 2.57 & $73.00 \mathrm{a}$ & 2.09 & $70.00 \mathrm{a}$ & 2.00 \\
\hline 2. Pyrethrum & $90.00 \mathrm{~b}$ & 2.00 & $84.60 \mathrm{~b}$ & 1.22 & $81.50 \mathrm{~b}$ & 1.33 & $76.20 \mathrm{~b}$ & 0.92 \\
\hline 3. Nurelle D & $96.80 \mathrm{c}$ & 1.93 & $91.00 \mathrm{c}$ & 1.91 & $84.60 \mathrm{~b}$ & 1.46 & $77.90 \mathrm{~b}$ & 0.95 \\
\hline $\mathrm{LSD}_{0.05 \%}$ & 3.821 & & 3.951 & & 3.315 & & 2.762 & \\
\hline \multicolumn{9}{|l|}{2013} \\
\hline \multicolumn{9}{|l|}{ Tychius flavus } \\
\hline 1. NeemAzal & $20.4 a$ & 2.43 & $33.2 \mathrm{a}$ & 2.62 & $39.7 a$ & 2.08 & $32.5 a$ & 2.50 \\
\hline 2. Pyrethrum & $62.1 \mathrm{~b}$ & 1.80 & $57.1 \mathrm{~b}$ & 2.64 & $50.5 b$ & 1.41 & $35.2 a$ & 2.65 \\
\hline 3. Nurelle D & $81.5 \mathrm{c}$ & 2.19 & $70.4 \mathrm{c}$ & 2.27 & $66.7 \mathrm{c}$ & 2.85 & $60.7 b$ & 2.66 \\
\hline $\operatorname{LSD}_{0.05 \%}$ & 4.308 & & 5.024 & & 4.377 & & 5.203 & \\
\hline \multicolumn{9}{|c|}{ Adelphocoris lineolatus } \\
\hline 1. NeemAzal & $36.7 a$ & 2.08 & $42.3 a$ & 3.22 & $49.6 a$ & 3.67 & $44.0 \mathrm{a}$ & 2.65 \\
\hline 2. Pyrethrum & $69.1 \mathrm{~b}$ & 3.20 & $62.0 \mathrm{~b}$ & 3.00 & $57.3 b$ & 2.52 & $50.7 b$ & 3.22 \\
\hline 3. Nurelle D & $87.3 c$ & 2.52 & $81.3 c$ & 2.53 & $71.0 \mathrm{c}$ & 3.61 & $64.4 \mathrm{c}$ & 2.60 \\
\hline $\operatorname{LSD}_{0.05 \%}$ & 5.276 & & 5.853 & & 6.608 & & 5.662 & \\
\hline \multicolumn{9}{|c|}{ Acyrthosiphon pisum } \\
\hline 1. NeemAzal & $45.5 a$ & 2.25 & $54.1 \mathrm{a}$ & 1.90 & $57.5 a$ & 2.28 & $58 a$ & 3.61 \\
\hline 2. Pyrethrum & $73.4 b$ & 1.71 & $66.9 \mathrm{~b}$ & 3.41 & $60.3 a$ & 3.51 & $58.8 \mathrm{a}$ & 2.84 \\
\hline 3. Nurelle D & $88 c$ & 2.00 & $80.4 c$ & 2.43 & $72.1 \mathrm{~b}$ & 2.80 & $67.5 b$ & 2.25 \\
\hline $\mathrm{LSD}_{0.05 \%}$ & 3.991 & & 5.299 & & 5.809 & & 5.892 & \\
\hline \multicolumn{9}{|l|}{2014} \\
\hline \multicolumn{9}{|l|}{ Tychius flavus } \\
\hline 1. NeemAzal & $37.5 a$ & 3.56 & $42.9 a$ & 1.90 & $50.0 a$ & 2.00 & $38.9 a$ & 1.68 \\
\hline 2. Pyrethrum & $76.3 b$ & 1.62 & $67.1 b$ & 1.47 & $60.4 b$ & 2.23 & $44.4 b$ & 2.16 \\
\hline 3. Nurelle D & $90.0 \mathrm{c}$ & 2.00 & $78.6 \mathrm{c}$ & 1.40 & $70.2 \mathrm{c}$ & 1.71 & $65.6 c$ & 2.20 \\
\hline $\begin{array}{l}\mathrm{LSD}_{0.05} \\
\text { Adelphocoris lin }\end{array}$ & 5.063 & & 3.21 & & 3.976 & & 4.051 & \\
\hline 1. NeemAzal & $50.0 a$ & 1.73 & $57.1 \mathrm{a}$ & 1.33 & $60.4 a$ & 0.72 & $61.8 \mathrm{a}$ & 1.97 \\
\hline 2. Pyrethrum & $77.5 b$ & 0.76 & $71.4 b$ & 1.06 & $72.1 b$ & 1.47 & $68.5 b$ & 1.29 \\
\hline 3. Nurelle D & $90.3 c$ & 0.76 & $85.7 c$ & 1.03 & $80.0 \mathrm{c}$ & 0.60 & $71.0 \mathrm{~b}$ & 1.25 \\
\hline $\mathrm{LSD}_{0.05 \%}$ & 2.349 & & 2.292 & & 2.016 & & 3.072 & \\
\hline Acyrthosiphon & & & & & & & & \\
\hline 1. NeemAzal & $55.4 a$ & 1.44 & $60.3 a$ & 1.62 & $67.8 a$ & 2.46 & $69.1 \mathrm{a}$ & 2.90 \\
\hline 2. Pyrethrum & $82.8 b$ & 1.06 & $79.1 b$ & 1.21 & $77.6 \mathrm{~b}$ & 2.03 & $73.9 b$ & 1.60 \\
\hline 3. Nurelle D & $92.4 \mathrm{c}$ & 1.04 & $85.2 \mathrm{c}$ & 1.59 & $81.5 b$ & 2.14 & $77.8 \mathrm{~b}$ & 1.93 \\
\hline $\operatorname{LSD}_{0.05 \%}$ & 2.397 & & 2.960 & & 4.428 & & 4.423 & \\
\hline
\end{tabular}

*Means within columns followed by the same letter are not significantly different ( $p>0.05)$. 1DAT: One day after treatment, 5DAT: Five days after treatment, 7DAT: Seven days after treatment, 9DAT: Nine days after treatment, Sd: Standard deviation, E: Efficacy

respectively. Pyrethrum showed significantly a stronger toxic effect $(P<0.05)$ from the first to the ninth day $(77.5$ $68.5 \%)$ and provided substantially better plant protection.
Nurelle D was characterized by the highest efficacy as during the last reporting day the effect was equalizing with that of the Pyrethrum with minor differences. 
Organic products were most effective against $A$. pisum. Increasing efficacy of NeemAzal reached satisfactory values of 67.8 and 69.1 percent of the seventh and ninth day after the application. Pyrethrum exhibited strong efficacy throughout the reporting period in the range $73.9-82.8 \%$ and differences between bioinsecticides were significant $(P<0.05)$. In compared with standard its toxic action was less expressed during the first reporting days as the seventh and ninth day it approached the effect of synthetic insecticide with minor differences between them.

Similar results regarding the efficacy of these insecticide products reported Andreev et al. (2012). Authors found that there were differences in susceptibility between rosy apple aphids (Dysaphis plantaginea Pass.) and spirea aphids (Aphis spiraecola Patch.) in relation to these insecticides and NeemAzal and Pyrethrum were ineffective against spirea aphids while Pyrethrum showed flash action and resulted in a better control than NeemAzal against rosy apple aphids. Its efficacy was $100 \%$ on the first day after treatment. The action of NeemAzal was delayed and a good effect was reached three days after treatment.

Organic products with insecticidal effect have different mechanisms of action and manifestation of toxicity. The reason for that was probably due to the biological action of their active substances. NeemAzal contains biologically active substances from the limonoid group and shows significant insecticidal, growth-inhibiting and antifeedant effects (Morgan, 2009). The product occurs slowly initiation action and growing after-action. It ceases the development of larvae, they become less mobile, stop eating and die within a few days (Mordue, Blackwell, 1993), which explains the later toxicity exhibited by that biological insecticide.

Unlike NeemAzal initial effects of Pyrethrum include paralysis followed by quick death (Pavela, 2009) or so-called "knock-down" effect. The active ingredients of pyrethrum extract contain a mixture of pyrethrin I, pyrethrin II, cinerin I, and cinerin II, obtained from dried flowers of the pyrethrum daisy. Pyrethrins I and II account for a major part of the insecticidal activity and have been used as insecticides since ancient times (Pavela, 2009). How pyrethrins act is related to their ability to affect the sodium channel function in the neuronal membranes.

A similar Pyrethrum effect showed and synthetic insecticide.

The results of the three-factor analysis of variance showed that significant effect on the variation in the product efficacy against $T$. flavus had both the year (factor A, respectively weather conditions during the year of study) and the type of insecticide (factor B), and the days after treatment $(\mathrm{C})$, while about the interaction between them significant influence was established only between factors $\mathrm{B} \times \mathrm{C}$ (Table 4).

A dominant influence on the efficacy variation had the type of insecticide $(60.8 \%)$, an intermediate position held the impact of the year $(17.8 \%)$ and the interaction between factors $\mathrm{B} \times \mathrm{C}(12.4 \%)$ while the effect of days after treatment (factor $\mathrm{C}$ ) reached only $7.1 \%$.

It was found a significant effect of systematic factors on the variability of the insecticide efficacy as regards $A$. lineolatus and $A$. pisum. The type of the tested product had the strongest influence (56.3 and 52.4\% respectively), followed by factors year of treatment (23.2 and $24.9 \%$ respectively)

\begin{tabular}{|c|c|c|c|c|}
\hline Source of variation & $\begin{array}{l}\text { Degrees } \\
\text { of freedom } \\
\text { (df) }\end{array}$ & $\begin{array}{l}\text { Sum of } \\
\text { squares } \\
\text { (SS) }\end{array}$ & $\begin{array}{c}\text { Influence } \\
\text { of factor, } \\
\%\end{array}$ & $\begin{array}{l}\text { Mean } \\
\text { square } \\
\text { (MS) }\end{array}$ \\
\hline \multicolumn{5}{|l|}{ Tychius flavus } \\
\hline Total & 107.0 & 34940.5 & 100.0 & 326.5 \\
\hline Variants & 35.0 & 34614.3 & $99.1^{*}$ & 989.0 \\
\hline Factor A - Year & 2.0 & 6171.8 & $17.8^{*}$ & 3085.9 \\
\hline Factor B -Insecticide & 2.0 & 21055.2 & $60.8^{*}$ & 10527.6 \\
\hline $\begin{array}{l}\text { Factor } \mathrm{C} \text {-Days after } \\
\text { treatment }\end{array}$ & 3 & 2456.34 & $7.1^{*}$ & 818.8 \\
\hline$A \times B$ & 4.0 & 220.5 & 0.6 & 55.1 \\
\hline$A^{*} C$ & 6.0 & 289.536 & 0.8 & 48.3 \\
\hline $\mathrm{B}^{*} \mathrm{C}$ & 6.0 & 4303.2 & $12.4^{*}$ & 717.2 \\
\hline$A^{*} B^{*} C$ & 12.0 & 117.771 & 0.3 & 9.8 \\
\hline Pooled error & 72.0 & 326.2 & 0.9 & 4.5 \\
\hline \multicolumn{5}{|l|}{ Adelphocoris lineolatus } \\
\hline Total & 107.0 & 22115.6 & 100.0 & 206.7 \\
\hline Variants & 35.0 & 21783.6 & $98.5^{*}$ & 622.4 \\
\hline Factor A - Year & 2.0 & 5046.5 & $23.2^{*}$ & 2523.3 \\
\hline Factor B -Insecticide & 2.0 & 12270.5 & $56.3^{*}$ & 6135.3 \\
\hline $\begin{array}{l}\text { Factor C -Days after } \\
\text { treatment }\end{array}$ & 3 & 980.402 & 4.5 & 326.8 \\
\hline$A \times B$ & 4.0 & 568.8 & 2.6 & 142.2 \\
\hline$A^{*} C$ & 6.0 & 98.9439 & 0.5 & 16.5 \\
\hline $\mathrm{B}^{\star} \mathrm{C}$ & 6.0 & 2730.4 & $12.5^{\star}$ & 455.1 \\
\hline$A^{*} B^{*} C$ & 12.0 & 87.9767 & 0.4 & 7.3 \\
\hline Pooled error & 72.0 & 332.0 & 1.5 & 4.6 \\
\hline \multicolumn{5}{|l|}{ Acyrthosiphon pisum } \\
\hline Total & 107.0 & 16185.3 & 100.0 & 151.3 \\
\hline Variants & 35.0 & 15862.1 & $98.0^{*}$ & 453.2 \\
\hline Factor A - Year & 2.0 & 3950.8 & $24.9^{*}$ & 1975.4 \\
\hline Factor B -Insecticide & 2.0 & 8317.0 & $52.4^{*}$ & 4158.5 \\
\hline $\begin{array}{l}\text { Factor C -Days after } \\
\text { treatment }\end{array}$ & 3 & 580.111 & 3.7 & 193.4 \\
\hline$A \times B$ & 4.0 & 206.9 & 1.3 & 51.7 \\
\hline$A^{*} C$ & 6.0 & 129.24 & 0.8 & 21.5 \\
\hline $\mathrm{B}^{*} \mathrm{C}$ & 6.0 & 2640.8 & $16.6^{*}$ & 440.1 \\
\hline$A^{*} B^{*} C$ & 12.0 & 37.2926 & 0.2 & 3.1 \\
\hline Pooled error & 72.0 & 323.2 & 2.0 & 4.5 \\
\hline
\end{tabular}

${ }^{*}$ Significant at $5 \%$ level of probability 
Nikolova: Effects of bio insecticides on insect pests

Table 5: Alfalfa seed productivity under influence of organic products, $\mathbf{k g ~ h a}^{-1}$

\begin{tabular}{|c|c|c|c|c|c|c|c|c|}
\hline Variants & 2012 & Sd & 2013 & Sd & 2014 & Sd & Average & Sd \\
\hline NeemAzal & $250.7 a b^{*}$ & 9.0 & $198.0 a$ & 6.1 & $214.8 \mathrm{a}$ & 5.0 & $221.1 \mathrm{a}$ & 17.8 \\
\hline Pyrethrum & $296.0 \mathrm{bc}$ & 33.1 & $226.4 a b$ & 26.0 & $257.5 b$ & 24.0 & $260.0 b$ & 27.6 \\
\hline Nurelle D & $314.1 \mathrm{c}$ & 13.1 & $260.1 b$ & 44.5 & $284.1 b$ & 11.8 & $286.1 b$ & 11.1 \\
\hline Control & $217.9 a$ & 40.7 & $198.3 a$ & 2.1 & $198.5 a$ & 11.1 & $190.1 \mathrm{a}$ & 9.1 \\
\hline LSD0.05\% & \multicolumn{2}{|c|}{51.578} & \multicolumn{2}{|c|}{48.933} & \multicolumn{2}{|c|}{27.654} & \multicolumn{2}{|c|}{33.705} \\
\hline
\end{tabular}

*Means within columns followed by the same letter are not significantly different ( $>0.05)$; Sd: Standard deviation

while the interaction between the type of product and days after treatment had the weakest influence (12.5 and $16.6 \%$ respectively). Days after treatment factor did not significantly influence the efficacy variation.

Similar results reported Yankova and Masheva (2010) according to which significant and dominant influence on the efficacy had the type of tested products with insecticidal action in compared with days after treatment factor as regards the cotton aphid (Aphis gossypii Glov.) and greenhouse whitefly (Trialeurodes vaporariorum West).

The productivity of alfalfa grown for seed production was influenced positively by the application of organic products, which are the object of this study (Table 5). The application of the products NeemAzal and Pyrethrum having an insecticidal action was related to the realization of higher productivity on average for the period by 8.0 and $26.9 \%$ respectively, but significant differences were found only between control and Pyrethrum. The use of synthetic insecticide Nurelle D as a standard was associated with the realization of the highest productivity $(39.7 \%$ on average), but compared with the yield seeds realized after application of Pyrethrum as in the three experimental years as well as the average for the period, the differences between them were insignificant. That was determined by the biological activity of pyrethrin substances whose efficacy approached and was comparable to that of Nurelle D.

By the analysis of variance with regard to the alfalfa seed yield (Table 6), it was established that the years respectively meteorological conditions during the three years and type of products had a significant influence on the parameter. The type of applied insecticide was distinguished with a dominant influence $(68.6 \%$ of the total variation) due to differences in the action mechanism and active substances of the tested plant protection products. The interaction between year conditions and products $(\mathrm{A} \times \mathrm{B}-3.9 \%)$ was not significant that showed their weak influence on the alfalfa seed yield.

The use of plant pesticides has been recommended ever more as a suitable alternative for plant protection with minimum negative risks (Isman, 2006; Pavela, 2007). Pyrethrum and NeemAzal are applicable to the conditions
Table 6: Analysis of variance with reference to seed productivity

\begin{tabular}{lcccc}
$\begin{array}{l}\text { Source of } \\
\text { variation }\end{array}$ & $\begin{array}{c}\text { Degrees } \\
\text { of freedom } \\
\text { (df) }\end{array}$ & $\begin{array}{c}\text { Sum of } \\
\text { squares } \\
\text { (SS) }\end{array}$ & $\begin{array}{c}\text { Influence } \\
\text { of factor, } \\
\%\end{array}$ & $\begin{array}{c}\text { Mean } \\
\text { square } \\
\text { (MS) }\end{array}$ \\
\hline Total & 35.0 & 66589.5 & 100.0 & 1902.6 \\
Variants & 11.0 & 53457.1 & $75.4^{*}$ & 4859.7 \\
Factor A - Year & 2.0 & 14686.4 & $27.5^{*}$ & 7343.2 \\
FactorB -Insecticide & 3.0 & 36672.9 & $68.6^{*}$ & 12224.3 \\
AxB & 6.0 & 2097.7 & 3.9 & 349.6 \\
Pooled error & 24.0 & 13132.4 & 24.6 & 547.2 \\
\hline
\end{tabular}

${ }^{*}$ Significant at $5 \%$ level of probability

of an organic farming, providing very high protection against phytophagous bugs and aphids.

\section{CONCLUSION}

Organic products were most effective against $A$. pisum. Increasing efficacy of NeemAzal reached satisfactory values of 67.8 and 69.1 percent of the seventh and ninth day after the application. Pyrethrum exhibited strong efficacy throughout the reporting period in the range 73.9-82.8\% and differences between bioinsecticides were significant. In compared with standard its toxic action after the fifth day was approached the effect of synthetic insecticide with minor differences between them. Bioinsecticides exhibited good control against $A$. lineolatus as the trend of the better protective effect of Pyrethrum was retained. A dominant influence on the efficacy variation and seed productivity had the type of insecticide followed by factors year of treatment. The productivity of alfalfa grown for seed production realized after application of Pyrethrum significantly exceeded control and was comparable to that of Nurelle D.

\section{REFERENCES}

Andreev, R., H. Kutinkova and D. Rasheva. 2012. Nonchemical control of Aphis spiraecola Patch. and Dysaphis plantaginea Pass. On apple. J. Biopesticides. 5 Suppl: 239-242.

Barbercheck, M. E. 2011. Biology and management of aphids in organic production systems. Organic Publications Article. Available from: http://www.extention.org/pages/60000.

Godfrey, L., P. Goodell, V. Barlow, E. Natwick and R. Long. 2013. Insect Pest Management Issues in Alfalfa - Challenges and Questions. Western Alfalfa \& Forage Symposium. December 12; 2013. 
Gombert, J., J. Dumortier, V. Prud'Homme, A. Dupuy, B. Frerot and F. Deneufbourg. 2015. Towards integrated crop protection to control Tychius aureolus in alfalfa seed crops. $5^{\text {th }}$ Conférence Internationale sur les Méthodes Alternatives de Protection des Plantes, 1113 Mars, 2015, Nouceau Sièle, Lille, France; 2015. Pp. 549-558.

Goplen, B. P., H. Baenzizer, L. D. Bailey, A. T. H. Gross, M. R. Hanna, R. K. Michaud, W. Richards and J. Waddington. 1987. Growing and Managing Alfalfa in Canada, Agriculture Canada Publication 1705/E, Ottawa, O. N., p. 50.

Henderson, C. F. and E. W. Tilton. 1955. Tests with acaricides against the brow wheat mite. J. Econ. Entomol. 48: 157-161.

Isman, M. B. 2005. Problems and opportunities for the commercialization of insecticides. In: Regnault-Roger, C., B. J. R. Philogene and R. Vincent, (Eds.), Biopesticides of Plant Origin, Lavoisier, Paris, Pp. 283-291.

Isman, M. B. 2006. The role of botanical insecticides, deterrents, and repellents in modern agriculture and an increasingly regulated world. Annu. Rev. Entomol. 51: 45-66.

Karagić, Đ., G. Jevtić and D. Terzić. 2010. Forage legumes seed production in Serbia. Biotechnol. Anim. Husbandry. 26: 133-149.

Kraiss, H. and E. M. Cullen. 2008b. Insect growth regulator effects of azadirachtin and neem oil on survivorship, development and fecundity of Aphis glycines (Homoptera: Aphididae) and its predator, Harmonia axyridis (Coleoptera: Coccinellidae). Pest Manag. Sci. 64(6): 660-668. DOI: 10.1002/ps.1541.

Kraiss, H. and E. M. Cullen. 2008a. Efficacy and nontarget effects of reduced-risk insecticides on Aphis glycines (Hemiptera: Aphididae) and its biological control agent Harmonia axyridis (Coleoptera: Coccinellidae). J. Econom. Entomol. 101(2): 391-398.

Lugić, Z., D. Lazarević, P. Erić, V. Mihajlović and S. Vučković. 2010. The state of forage crops production in Serbia. Biotechnol. Anim Husbandry 26(Special issue): 29-47.

Mordue, (Luntz), A. J. and A. Blackwell. 1993. Azadirachtin: An update. J. Insect Physiol. 39: 903-924.

Morgan, E. D. 2009. Azadirachtin, a scientific gold mine. Bioorgan. Med. Chem. 17: 4096-4105.

Mouffok, B., E. Raffy, N. Urruty and J. Zicola. 2007/2008. Le Neem, Un Insecticide Biologique Efficace. (Projet Tutoré Du S2), Université Paul Sabatier, Auch, p. 14.
Ng, J. C. K. and K. L. Perry. 2004. Transmission of plant viruses by aphid vectors. Mol. Plant Pathol. 5: 505-511.

Pavela, R. 2007. Possibilities of botanical insecticide exploitation in plant protection. Pest Technol. 1: 47-52.

Pavela, R. 2009. Effectiveness of some botanical insecticides against Spodoptera littoralis Boisduvala (Lepidoptera: Noctudiae), Myzus persicae Sulzer (Hemiptera: Aphididae) and Tetranychus urticae Koch (Acari: Tetranychidae). Plant Protect. Sci. 45(4): 161-167.

Sadeghi, A., E. M. Van Damme and G. Smagghe. 2009. Evaluation of the susceptibility of the pea aphid, Acyrthosiphon pisum, to a selection of novel biorational insecticides using an artificial diet. J. Insect Sci. 9: 65.

Sekulić, R., S. Katić, Đ. Karagić and T. Kereši. 2005. Plant Bugs Pests of Alfalfa and Clover. Doctoral Thesis, Faculty of Agriculture, Department of Plant and Environmental Protection "Dr Pavle Vukasović". Novi Sad. 5: 517-526. (In Serbian).

Shannag, H. S., J. L. Capinera and N. M. Freihat. 2014. Efficacy of different neem-based biopesticides against green peach aphid, Myzus persicae (Hemiptera: Aphididae). Int. J. Agric. Policy Res. 2(2): 61-68.

Trdan, S., A. Cirar, K. Bergant, L. Andjus, M. Kač, M. Vidrih and L. Rozman. 2007. Effect of temperature on efficacy of three natural substances to Colorado potato beetle, Leptinotarsa decemlineata (Coleoptera: Chrysomelidae). Acta Agric. Scand. Sec. B. Soil Plant Sci. 57(4): 293-296.

Uddin, M. J. 2005. Insects of alfalfa in Manitoba with particular reference to Lygus spp., Adelphocoris lineolatus (Hemiptera: Miridae) and Acyrthosiphon pisum (Homoptera: Aphididae) and their natural enemies. Ph.D. Dissertation, University of Manitoba, Winnipeg.

Wheeler, A. G. 2001. Biology of the Plant Bugs (Hemiptera: Miridae): Pests, Predators, Opportunists, Cornell University Press, Ithaca, N. Y.

Yankova, V. and S. Masheva. 2010. Effectiveness of Agri $50 \mathrm{NF}$ and Agricole bioproducts against diseases and pest in greenhouse cucumbers. Agricultural University - Plovdiv, Scientific Works, Jubilee Scientific Conference with International Participation Traditions and Challenges of Agricultural Education, Science and Business. Vol. LV. Book. 2. 2010. (In Bulgarian). 